\title{
ENERGIA EÓLICA E SOLAR: FONTES ALTERNATIVAS DE GERACCÃO OU INDISPENSÁVEIS AO DESENVOLVIMENTO SUSTENTÁVEL?
}

Jorge Miguel Calandrini de Azevedo Neto

Bacharel Em Direito pelo Centro Universitário do Estado do ParáCESUPA (2019) com um 1 semestre de mobilidade na Universidade do Porto - FDUP pelo programa ERASMUS (2017).

E-mail: jorge.miguelcalandrini@hotmail.com

\section{RESUMO}

O presente trabalho tem o objetivo de contribuir para a compreensão do conceito de desenvolvimento sustentável, demonstrando a transição do conceito de desenvolvimento para o desenvolvimento sustentável, aludindo sobre as suas dimensões defendidas pelos autores Sachs e Juárez De Freitas. Cada dimensão possui características próprias que devem ser satisfeitas para se alcançar o pleno desenvolvimento sustentável. O desenvolvimento sustentável deve estar ligado às energias limpas, verdadeiramente renováveis, pois é o mais consonante com o aludido por Sachs e Juarez, bem como pelos Tratados ratificados pelo Brasil. É a partir dessa compreensão que o Estado brasileiro deve investir mais nos setores de energia eólica e solar. Ao final conclui-se que o desenvolvimento sustentável transcende o simples crescimento econômico, devendo ser conciliado com a proteção do meio ambiente, buscando formas de energias limpas que gerem menos violações de direitos.

PALAVRAS-CHAVE: Direito Ambiental. Desenvolvimento Sustentável. Dimensões.

\section{WIND AND SOLAR ENERGY: ALTERNATIVE SOURCES GENERATING OR INDISPENSABLE TO SUSTAINABLE DEVELOPMENT?}

\begin{abstract}
This paper aims to contribute to the understanding of the concept of sustainable development, demonstrating the transition from the concept of development to sustainable development, alluding to its dimensions defended by authors Sachs and Juárez De Freitas. Each dimension has its own characteristics, only full
\end{abstract}


sustainable development being achieved if all are fulfilled. Sustainable development must be linked to clean, truly renewable energies, since it is the most consonant with Sachs and Juarez and the treaties ratified by Brazil. It is from this understanding that the Brazilian. In the end, it is concluded that sustainable development transcends simple economic growth and must be reconciled with the protection of the environment.

KEYWORDS: Environmental Law. Sustainable development. Dimensions.

\section{INTRODUÇÃO}

Este artigo visa demonstrar a necessidade de aplicação do desenvolvimento sustentável no Brasil, apresentando a transição do conceito de desenvolvimento para o desenvolvimento sustentável, perpassando sobre as suas dimensões através dos conceitos dos autores Sachs e Juárez De Freitas. Além disso, partindo desta conceituação analisamos que as energias solares e eólicas são mais coerentes com as dimensões preceituadas pelos autores, implicando ao Estado brasileiro um dever de investir mais nesses setores energéticos, pois segundo dados do Ministério de Minas e Energia de 2017 a energia solar e eólica correspondem a apenas 15\% da matriz energética nacional, enquanto a energia proveniente de hidrelétricas representa mais de $60 \%$ da matriz nacional. (BRASIL, 2017)

Consta na Constituição Federal de 1988 (CF/88) o dever do Estado Brasileiro e dos cidadãos de promover a preservação do ambiente, conforme o artigo 225 da CF/88. Percebemos com essa previsão legal e com os Tratados Internacionais, ratificados pelo Brasil, que o país se encontra legitimado em um Estado Ambiental, entretanto, a política nacional de crescimento energético é principalmente voltada para as construções de hidrelétricas na região norte do país, construções que geram demasiados impactos ambientais, sociais e até econômicos, danos incompatíveis com o dever de preservação preceituado pela Constituição Brasileira.

Dessa forma, acreditamos que para a real efetivação do desenvolvimento sustentável e as suas dimensões defendidas por Sachs e Juaréz possam ser alcançadas em solo nacional é necessário maiores investimentos do Estado ou buscando parcerias públicas- privado nas energias solar e eólica, visto o grande potencial nacional subutilizado. Aliado a esse ideal de sempre progredir, o Estado deve fomentar o desenvolvimento de novas tecnologias, visando sempre o aprimoramento das fontes renováveis e o constante melhoramento do meio ambiente e sua proteção. 


\section{A TRANSIÇÃO DE DESENVOLVIMENTO PARA DESENVOLVIMENTO SUSTENTÁVEL}

Com a previsão no texto constitucional tutelando o meio ambiente como bem jurídico fundamental, é correto dizer que o Brasil se encontra num Estado Democrático Ambiental, passando a ter o dever de preservar e proteger as futuras gerações. Assim, o poder público e os cidadãos devem fiscalizar qualquer ação nociva ao meio ambiente ecologicamente equilibrado, como preceitua o artigo $225, \S 1$, in verbis:

Art 225. Todos têm direito ao meio ambiente ecologicamente equilibrado, bem de uso comum do povo e essencial à sadia qualidade de vida, impondo-se ao Poder Público e à coletividade o dever de defendê-lo e preservá-lo para as presentes e futuras gerações.

$\S$ I - Para assegurar a efetividade desse direito, incumbe ao Poder Público:

I - Preservar e restaurar Os processos ecológicos essenciais e promover o manejo ecológico das espécies e ecossistemas;

II - Preservar a diversidade e a integridade do patrimônio genético do País e fiscalizar as entidades dedicadas à pesquisa e manipulação de material genético;

III - definir, em todas as unidades da Federação, espaços territoriais e seus componentes a serem especialmente protegidos, sendo a alteração e a supressão permitidas somente através de lei, vedada qualquer utilização que comprometa a integridade dos atributos que justifiquem sua proteção;

IV - Exigir, na forma da lei, para instalação de obra ou atividade potencialmente causadora de significativa degradação do meio ambiente, estudo prévio de impacto ambiental, a que se dará publicidade;

V - Controlar a produção, a comercialização e o emprego de técnicas, métodos e substâncias que comportem risco para a vida, a qualidade de vida e o meio ambiente;

VI - Promover a educação ambiental em todos os níveis de ensino e a conscientização pública para a preservação do meio ambiente;

VII - proteger a fauna e a flora, vedadas, na forma da lei, as práticas que coloquem em risco sua função ecológica, provoquem a extinção de espécies ou submetam os animais a crueldade. (BRASIL, 1988)

A celeuma que envolve o desenvolvimento sustentável não irá terminar, sendo sempre um tema atual e de muita relevância, visto que sempre haverá o embate entre o crescimento econômico e a preservação ambiental. Sendo importante conceituar o desenvolvimento sustentável, pois se percebe que o princípio está em total consonância com o preceituado no artigo $225 \mathrm{CF}$, todavia, antes de se falar em sustentabilidade, é de suma importância conceituar “desenvolvimento", palavra muito utilizada antes do acréscimo de "sustentável”.

O desenvolvimento possui estrita relação com o crescimento econômico, é possível 
perceber sua relação extrínseca defendida por autores como Adam Smith. O autor alude que com o crescimento econômico, haverá mais empregos, consequentemente uma economia ativa que irá propiciar o desenvolvimento para seus cidadãos (HUNT. 2005). Percebe-se que este entendimento ainda é muito presente atualmente, um exemplo é o Produto Interno Bruto (PIB), conhecido por ser uma aritmética extremamente objetiva para se chegar ao seu resultado. Sendo assim, o crescimento econômico pode ser interpretado como desenvolvimento, mas não se restringe a isso.

O PIB não contabiliza, por exemplo, a perda de recursos naturais pelo crescimento econômico, não sendo coerente com o ideal de desenvolvimento sustentável. Visando a modificar a forma de se medir o crescimento e forma, outros índices foram criados frente ao PIB, como por exemplo, o "Índice de Desenvolvimento Humano" (IDH) com o intuito de se quantificar o crescimento de um país além do crescimento econômico. (MOREIRA. 2012)

O desenvolvimento está ligado ao modelo de liberalismo econômico, visando à maximização do lucro com o mínimo possível de interferência estatal para regular as ações humanas. É clarividente que a culpa dos danos causados não é exclusiva do liberalismo, haja vista que o pensamento predominante na época era de um capitalismo predatório que não respeita as liberdades individuais mínimas, contrariando a doutrina do liberalismo que prega fundamentalmente a defesa dos direitos fundamentais.

Diante desse cenário, o desenvolvimento desenfreado não leva em consideração o meio ambiente como um limitador do crescimento, apenas como uma fonte inesgotável de desenvolvimento econômico gerando consequências irreversíveis. Percebe-se essa interpretação em Corsi, sobre "A Riqueza Das Nações", do renomado autor do liberalismo Adam Smith reflete o pensamento:

[...] Smith concebe a riqueza de uma nação como um processo fundamentalmente social. A riqueza de uma nação não depende de sua dotação de recursos naturais. "Qualquer que seja o solo, o clima ou a extensão do território de uma determinada nação, a abundância ou escassez do montante anual de bens que disporá, nessa situação específica, dependerá necessariamente das duas circunstâncias [...] primeiro, [da] habilidade, destreza e bom senso com os quais seu trabalho for executado; em segundo lugar, [da] proporção entre os números dos que executam trabalho útil e dos que não executam tal trabalho. (CORSI, 2011).

É nítida a concepção que permeou por muito tempo aduzindo que a natureza é uma fonte inesgotável de matéria prima que deve ser explorada para que os Estados- nações 
obtenham mais crescimento econômico, mais tecnologias e consequentemente um crescimento social. Diante dessa percepção a degradação do meio ambiente foi nefasta para o mundo, gerando perda de biodiversidades e impossibilitando a volta de um "status quo" irreparável, sem que o esperado crescimento social fosse atingido, causando danos aos direitos humanos, principalmente, em comunidades mais vulneráveis.

Visando modificar este ideal de desenvolvimento, principalmente devido aos grandes danos ambientais com a exploração indiscriminada de matérias primas, iniciou-se uma transição de pensamento sobre o conceito de desenvolvimento que era ligado diretamente ao crescimento econômico para um ideal de desenvolvimento sustentável que considera outros fatores importantes além do econômico, se tornando uma matéria multidisciplinar, pois impacta na condição humana em várias searas. Como percebemos nas palavras de Sachs:

$$
\begin{aligned}
& \text { “... os objetivos do desenvolvimento vão bem além da mera } \\
& \text { multiplicação da riqueza material. O crescimento é uma condição } \\
& \text { necessária, mas de forma alguma suficiente (muito menos é um } \\
& \text { objetivo em si mesmo), para se alcançar a meta de uma vida melhor, } \\
& \text { mais feliz e mais completa para todos." (SACHS, 2004) }
\end{aligned}
$$

A visão clássica de desenvolvimento sustentável tem como base três princípios: a proteção ambiental, o incremento econômico e a equidade social. Essa conceituação surgiu em Estocolmo (1972) como mensagem para se reaprender a viver com o meio ambiente, utilizando-o de forma consciente (UFSC. 2009). Entretanto, foi na conferência em solo brasileiro, a Rio 92, que houve o início do imperativo do desenvolvimento sustentável, alertando sobre a necessidade de mudanças de comportamento, visando a um desenvolvimento consciente através do documento "Nosso Futuro Em Comum" (MEIO AMBIENTE. 2018). O relatório definia o desenvolvimento sustentável como aquele que busca o crescimento econômico aliado à satisfação das necessidades da sociedade sem comprometer o futuro das próximas gerações.

Importante salientar que existe uma corrente que considera o desenvolvimento sustentável um mito, fruto do pensamento pós-moderno da globalização. Para os defensores dessa corrente, o desenvolvimento sustentável é uma falácia para que haja um controle social pelos países mais desenvolvidos perante os considerados subdesenvolvidos, uma burocracia feita através de Tratados que estariam evitando o crescimento em países periféricos e servindo como uma "armadilha ideológica construída para perpetuar as relações assimétricas entre as 
minorias dominadoras e as maiorias dominadas", considerando o desenvolvimento sustentável, por certos doutrinadores, como um princípio "represa". (SACHS, 2004).

Apesar dessa corrente minoritária, o desenvolvimento sustentável hoje é visto como um princípio multidimensional e não de controle. O constitucionalista português Canotilho aduz sobre o conceito adotado pela doutrina sobre sustentabilidade, defendendo uma visão em sentido amplo. Para o autor português o princípio é uma diretriz que os Estados devem seguir, como demonstra:

A sustentabilidade em sentido amplo procura captar aquilo que a doutrina actual designa por "três pilares da sustentabilidade": (i) pilar I - a sustentabilidade ecológica; (ii) pilar II - a sustentabilidade económica; (iii) pilar III - a sustentabilidade social3. Neste sentido, a sustentabilidade perfila-se como um "conceito federador" que, progressivamente, vem definindo as condições e pressupostos jurídicos do contexto da evolução sustentável. No direito internacional, a sustentabilidade é institucionalizada como um quadro de direcção política nas relações entre os Estados (CANOTILHO, 2003)

A diretriz do desenvolvimento sustentável foi contemplada na Constituição de 1988, colocando-o como uma missão do Estado brasileiro conforme o artigo 225 da Constituição Federal, sendo encarado como um princípio norteador do direito ambiental que impõe a sociedade e ao Estado o dever de proteção aos ecossistemas através do princípio de solidariedade entre as gerações. O conceito de desenvolvimento sustentável está ligado com o crescimento de justiça social e respeito ao futuro, conforme a observação de Juarez Freitas (2011):

[...] trata-se do princípio constitucional que determina com eficácia direta e imediata, a responsabilidade do Estado e da sociedade pela concretização solidária do desenvolvimento material e imaterial, socialmente inclusivo, durável e equânime, ambientalmente limpo, inovador, ético e eficiente, no intuito de assegurar, preferencialmente de modo preventivo e precavido, no presente e no futuro, o direito ao bem-estar. (FREITAS, 2011).

O crescimento econômico é, sem dúvida, um dos fatores mais importantes do desenvolvimento sustentável, porém não o primordial, pois não adianta haver o crescimento de riquezas sem que essas sejam distribuídas resultando em uma melhor qualidade de vida. Sendo assim, Sachs afirma que dimensões devem ser alcançadas, como conceitua o autor polonês: “o que importa é deixar bem claro que o desenvolvimento não se confunde com crescimento 
econômico, que constitui apenas a sua condição necessária, porém não suficiente. (SACHS. 2008)".

Em solo nacional, Juarez De Freitas discorre sobre uma natureza multidimensional da sustentabilidade, captando-a em suas instâncias sociais, éticas, jurídicas-políticas, econômicas e ambientais, Juarez conceitua que:

Uma mera norma vaga, pois determina, numa perspectiva tópicosistemática, a universalização concreta e eficaz do respeito às condições multidimensionais da vida de qualidade, com o pronunciado resguardo do direito ao futuro [...], que se desdobra no princípio constitucional que determina, com eficácia direta e imediata, a responsabilidade do Estado e da sociedade pela concretização solidária do desenvolvimento material e imaterial, socialmente inclusivo, durável e equânime, ambientalmente limpo, inovador, ético e eficiente, no intuito de assegurar, preferencialmente de modo preventivo e precavido, no presente e no futuro, o direito ao bemestar. (JUAREZ. 2011).

O economista polonês Ignacy Sachs (1993) também defende que o desenvolvimento sustentável possui dimensões. Para o autor, o conceito possui dimensões que devem ser alcançadas para que ocorra o verdadeiro desenvolvimento, ou seja, para Sachs, sem se alcançar todas as dimensões, não haverá o desenvolvimento sustentável. (SACHS. 2004)

Logo se conclui que o Estado Ambiental de Direito só chegará ao seu fim com a realização de todas as dimensões do desenvolvimento sustentável. Visto que o ideal de desenvolvimento passou por uma transição conceitual para que os anseios e necessidades da sociedade sejam satisfeitos de forma a não impactar na existência e qualidade da vida humana, Sendo assim, o Estado promover incentivos em meios de energia renováveis, buscando parcerias públicas- privados, assim como o judiciário deve ser limitador das eventuais violações cometidas ou propostas em matéria legislativa pelo Estado para que o desenvolvimento sustentável possa ser aliado no combate às violações de direitos individuais e coletivos.

\section{AS DIMENSÕES DO DESENVOLVIMENTO SUSTENTÁVEL}

As dimensões do conceito são fruto do caráter multidisciplinar da matéria ambiental, visto que com a transição do conceito está em constante evolução, abrangendo diferentes aspectos para a sua perpetuação. A sustentabilidade possui um tripé claro que são as dimensões ecológica, econômica e social, entretanto, autores como Sachs consideram além 
deste tripé as dimensões psicológica, espacial e política. (SACHS, 2004).

Assim como Sachs (1993), Juarez de Freitas (2011), em seu livro "Sustentabilidade: Direito ao futuro" defende a inclusão de dimensões além do tripé já consolidado, com as dimensões: ética e a jurídica - política, bem como defende em sua obra o caráter intergeracional do direito ambiental, como explica:

\begin{abstract}
"Sustentabilidade é multidimensional, porque o bem-estar é multidimensional. Para consolidá-la, nesses moldes, indispensável cuidar do ambiental, sem ofender o social, o econômico, o ético e o jurídicopolítico." Continua afirmando que "todas essas dimensões entrelaçadas [...] compõe um quadro, da sustentabilidade como princípio constitucional e como valor". (FREITAS, 2011).
\end{abstract}

Ambos os autores compactuam do mesmo ideal sobre o tripé do desenvolvimento sustentável que é pacificado na doutrina. A primeira dimensão do é um conceito que sempre fez parte do ideal de desenvolvimento, a dimensão econômica. Para Sachs (2004) a Dimensão Econômica é realizada através do melhor uso dos recursos, fazendo uma gestão mais efetivas dos recursos e por um fluxo regular do investimento público e privado visando sempre a melhoria para a sociedade.

Percebemos no artigo 170 CF que versa sobre a ordem econômica e financeira do país, tem a presença do desenvolvimento sustentável e da preservação ambiental, impondo o dever estatal de respeitar tais princípios constitucionais, ou seja, demonstrando que o crescimento econômico nacional deve ser aliado com a preservação como percebemos:

Art. 170. A ordem econômica, fundada na valorização do trabalho humano e na livre iniciativa, tem por fim assegurar a todos existência digna, conforme os ditames da justiça social, observados os seguintes princípios:

I - Soberania nacional;

II - Propriedade privada;

III - Função social da propriedade;

IV - Livre concorrência;

$\mathrm{V}$ - Defesa do consumidor;

VI - Defesa do meio ambiente;

VII - Redução das desigualdades regionais e sociais;

VIII - Busca do pleno emprego;

IX - Tratamento favorecido para as empresas brasileiras de capital nacional de pequeno porte.

Parágrafo único. É assegurado a todos o livre exercício de qualquer atividade econômica, independentemente de autorização de órgãos públicos, salvo nos casos previstos em lei. (BRASIL, 1988).

A dimensão ecológica é a mais conhecida de todas. Segundo as dimensões [ca. 2015], 
essa dimensão emergiu nos anos 70 com o objetivo de mostrar que o ser humano não é dono supremo dos recursos mundiais, explorando-a de qualquer maneira. Sob essa perspectiva a dimensão ecológica exige o respeito à dinâmica do meio ambiente, ou seja, respeitar seu tempo e realizando a adequação entre a necessidade de crescimento com a preservação ambiental, colocando o indivíduo como parte integrante do ecossistema e não seu predador.

Segundo as dimensões [ca. 2015] a dimensão ecológica versa sobre a necessidade de se viver em paz, em harmonia com o meio ambiente, conservando a fauna e a flora, e fazendo a manutenção de ecossistemas, bem como da integridade climática. Para tanto, deve-se buscar mecanismos para o desenvolvimento com o mínimo de danos possíveis, devendo haver o investimento estatal nos recursos renováveis, como energias eólicas e solares que hoje representam uma ínfima parcela da matriz energética brasileira. Desta forma, o Estado deve investir conjuntamente com o setor privado na pesquisa de tecnologias limpas como ocorre com a energia proveniente de biomassa, gerando o desenvolvimento sem prejudicar o direito ao futuro.

Percebemos que a dimensão ecológica se propõe a demonstrar a importância de usar os recursos do planeta de forma consciente e útil, visando sempre menos impactos as comunidades à sociedade, demonstrando a importância de preservação da fauna e flora, não vendo o meio ambiente apenas como uma fonte de recursos.

Segundo as dimensões [ca. 2015], a dimensão social alude sobre a necessidade da equidade social, ou seja, a busca da chamada justiça social, para se alcançar baixos índices de pobreza, garantindo o acesso aos bens e à justiça de forma equitativa, sendo a busca de uma sociedade civilizada em que não haja apenas o direito à vida, mas sim o direito à vida digna com condições básicas de sobrevivência como saneamento básico, a defesa de direitos individuais frente às violações do Estado aos indivíduos.

O desenvolvimento é interdisciplinar, com estritas ligações em outras matérias, devendo o Estado combater as desigualdades históricas, agindo para minimizar a concentração de renda, assegurando que os indivíduos tenham as mesmas condições culturais e econômicas e para tanto o Estado deve sempre buscar por meio de novas tecnologias os benefícios ambientais e sociais a comunidade, mas não se verifica essa consonância de pensamento no governo brasileiro.

Segundo as dimensões [ca. 2015] a Dimensão Cultural é defendida somente por Sachs, estando ligada ao direito de memória que alerta sobre a necessidade de se conhecer o passado 
para não repetir os seus erros, essa dimensão pode ser percebida em uma frase no "Estádio Nacional do Chile" palco de prisões e torturas durante o governo de Pinochet que diz: "um povo sem memória é um povo sem futuro". Segundo as dimensões [ca. 2015] A dimensão cultural é extremamente importante para a preservação da história das sociedades com vistas a preservar as tradições e valores regionais que podem se perder para a eternidade, devendo o Estado garantir o direito constitucional a informação que se encontra no art. $5^{\circ}, \mathrm{XXXIII,} \mathrm{CF.}$

Segundo as dimensões [ca. 2015] a dimensão espacial tem ligação com o direito urbanístico de haver investimentos igualitários em todas as áreas das cidades, combatendo as desigualdades que já existem na formação das cidades e descentralizando com o intuito de evitar o inchaço nestes espaços.. Sobre o desenvolvimento espacial Sachs alude que:

A sustentabilidade espacial abrange a organização do espaço e obedece a critérios superpostos de ocupação territorial e entrelaçados em uma rede natural duradoura para tentar recuperar, com esta complexa e diversificada trama, a qualidade de vida, a biodiversidade e a escala humana em cada fragmento, em cada bairro do sistema (SACHS, 1993).

Segundo as dimensões [ca. 2015] a dimensão psicológica também é defendida apenas por Sachs, versa sobre a sensação, o sentimento das pessoas, ou seja, a noção de um ideal coletivo de preservação ambiental, um sentimento inconsciente em cada pessoa em que Estado e indivíduos estão combatendo juntas as degradações legislativas. Uma dimensão que implica a ética das ações humanas, corroborando com a dimensão ética defendida por Juarez (2011). A necessidade da dimensão psicológica é da força às ideias de preservação que estão em nós, como conceitua "Embora ocorram dentro do indivíduo, essas sensibilidades diferentes que permitem partilhar o mesmo meio ambiente de forma pacífica com outras pessoas e com as outras dimensões da sustentabilidade (JACOBI, 2003)."

Segundo as dimensões [ca. 2015] a dimensão ética da sustentabilidade é defendida por Juarez, mas percebe-se uma ligação com a dimensão psicológica de Sachs (CORREA, 2015). Na dimensão ética fica claro o caráter intergeracional defendido por Juarez (2011), ou seja, o meio ambiente não pertence a um indivíduo, grupo ou a uma geração, este pertence à eternidade. De modo que compete à sociedade atual a herança ambiental e social que serão passadas para as gerações futuras. Oriundo do conceito de solidariedade e fraternidade entre os seres humanos, havendo uma ligação intersubjetiva entre homem e natureza, devendo ter a consciência do respeito ao próximo através de valores morais e éticos que devem guiar as atitudes humanas, como alude: 
[...] a dimensão ética, no sentido de que todos os seres possuem uma ligação intersubjetiva e natural, donde segue a empática solidariedade como dever universalizável de deixar o legado positivo na face da terra, com base na correta compreensão darwiniana de seleção natural, acima das limitações dos formalismos kantianos e rawlsianos. (FREITAS, 2011).

Segundo as dimensões [ca. 2015] a percepção ética é individual, mas deve-se criar um ambiente de proteção ambiental como sugere Sachs na dimensão psicológica, ou seja, um sentimento em que todos os indivíduos atuam de maneira ética, enfrentando as regressões e as violações a direitos fundamentais como o meio ambiente. Portando, se perpetua nessa dimensão o ideal de igualdade entre todos os seres vivos, a não concordância com ações ou omissões que resultem em degradação ambiental e um engajamento da sociedade.

A dimensão política conceituada por Sachs (1993) ou jurídica- política como é denominada por Juarez (2016) constitui para o autor a mais importante de todas. Percebe-se que os autores possuem consonância sobre essa dimensão com pensamentos parecidos (CORREA, 2015). A dimensão jurídico-política visa a efetivar e desenvolver os direitos fundamentais dos presentes e futuras gerações, possuindo a missão de progredir legislativamente, sendo uma aliada do princípio ao não retrocesso, promovendo o desenvolvimento que gera crescimento social com base na dignidade humana e a proteção de direitos fundamentais inerentes ao conceito de sustentabilidade.

Dimensão jurídico-política ecoa o sentido de que a sustentabilidade determina, com eficácia direta e imediata, independentemente de regulamentação, a tutela jurídica do direito ao futuro e, assim, apresenta-se como dever constitucional de proteger a liberdade de cada cidadão (titular de cidadania ambiental ou ecológica), nesse status, no processo de estipulação intersubjetiva do conteúdo intertemporal dos direitos e deveres fundamentais das gerações presentes e futuras, sempre que viável diretamente (FREITAS, 2016).

Essa dimensão tem o objetivo de manter o alto padrão protetivo do meio ambiente, tendo estrita relação ao princípio da vedação ao retrocesso. Exigindo a tutela do direito, implicando na mutabilidade do pensamento clássico do desenvolvimento, como por exemplo, o reconhecimento do caráter de interdependência entre matérias com o direito ambiental. É clarividente que a dimensão jurídico-política constitui um limitador do poder público assim como o princípio ao não retrocesso, não admitindo a deterioração protetiva e por este motivo sendo considerado por Juarez (2016) como um dos mais importantes de todo, se não a mais importante dimensão. 
No atual cenário nacional se faz muito necessária a utilização da dimensão jurídicopolítica para que seja forçada a mudança de paradigma proposto pelo governo, por uma forma mais sustentável de crescimento. Acreditamos que privilegiar os investimentos em energias como solar e eólicas são as melhores opções atuais para buscar um crescimento energético sustentável.

Os investimentos nas fontes alternativas e mais renováveis que as hidrelétricas irão gerar segurança energética ao país, visto que se ocorre algum erro com as hidrelétricas as outras fontes representam uma parcela pequena do total da matriz energética nacional. Além disso, os impactos ambientais gerados pela energia solar e eólica são menores do que outras formas de energia e é por isso que grandes países investem cada vez mais nesses modelos como, por exemplo, os Estados Unidos que possuem as maiores usinas solares do mundo (SOLARVOLT, 2016).

\section{AS ENERGIAS RENOVÁVEIS: SOLAR E EÓLICA.}

As energias renováveis são a principal esperança do mundo para diminuir os gases de efeito estufa, reduzindo o aquecimento global e assim permitindo melhor qualidade de vida. $\mathrm{O}$ aumento no investimento nesses setores elétricos é tendência mundial, países do mundo todo estão cada vez mais dispostos a gastar com a tecnologia devido aos seus benefícios. Entretanto, o Brasil continua insistindo em construção de hidrelétricas mesmo que o seu potencial solar e eólico seja gigantesco. Hoje as energias solares e eólicas não chegam a representar 15\% da matriz energética (MME, 2017), deixando a oportunidade de que o Brasil seja uma referencia mundial no assunto alude Ricardo Baitelo:

A capacidade instalada em energia eólica no planeta vem crescendo $27 \%$ ao ano nos últimos dez anos. No Brasil, o cenário para a fonte não é diferente; em 2011, foram instalados $582 \mathrm{MW}$, ou um crescimento de $63 \%$ em relação ao ano anterior. A capacidade instalada atual já passa dos $1.500 \mathrm{MW}$ - o que coloca o país entre os vinte maiores produtores de energia eólica do mundo e a fonte já representa mais de $1 \%$ da eletricidade produzida no país. (BAITELO. 2012).

É inegável que há um crescimento de investimentos nesses setores está ocorrendo em solo nacional, seria errado dizer que não existe, mas é ínfimo perto do investimento em hidrelétricas, não havendo uma proporcionalidade entre a produção energética, não sendo uma estratégia inteligente, pois, imprevistos acontecem e depender apenas de um setor pode ser 
uma tragédia, como demonstra o doutor em planejamento energético Ricado Baitelo:

O aproveitamento do enorme potencial eólico é decisivo para a manutenção de uma matriz elétrica limpa e para a segurança energética do país. O parque hidrelétrico instalado no país depende fortemente do regime de chuvas, que vem sofrendo alterações diante do aquecimento global e, durante o período de secas, são acionadas termelétricas movidas a combustíveis fósseis para manter a oferta de energia no período. A geração eólica é mais intensa justamente nestes meses e seu emprego é decisivo para evitar emissões de gases estufa e o alto custo de operação dessas termelétricas. (BAITELO. 2012)

Atualmente mais de $60 \%$ da matriz energética nacional é produzida por hidrelétricas na Amazônia, enquanto as energias solar e eólicas juntas correspondem a apenas $15 \%$ da matriz energética. Essa concentração energética em uma forma de geração energia é maléfica ao país, visto que é de conhecimento geral a necessidade de diversificação de investimentos em qualquer setor, buscando não depender apenas um setor. Dessa forma, o incentivo de maiores investimentos em energia solar eólica é vital para o crescimento sustentável do país, sendo importante essa transição da política energética nacional para meios que promovam o desenvolvimento sustentável.

Portanto, verificamos que os impactos as sociedades nos parques eólicos e solares são muito inferiores a outras formas de energias (BAITELO, 2012), principalmente na questão ecológica. Dessa forma, é possível aliar o crescimento econômico de forma sustentável, sendo possível a eficácia do princípio do desenvolvimento sustentável, preceituado no artigo 170 $\mathrm{CF} / 88$, para que o dever de preservação elencado no artigo $225 \mathrm{CF} / 88$ seja cumprido pelo Estado.

\subsection{ENERGIA EÓLICA}

O potencial energético eólico do Brasil é grande, principalmente no nordeste do país e na região sul. Esse potencial se dar pelas grandes quantidades de terra que o país possui visto as suas dimensões continentais, bem como a riqueza natural de ventos com frequência nessas regiões. Além disso, percebemos que hoje se fala em criação de parques eólicos no meio do mar que representam grandes vantagens sócio-ambientais, como demonstra Ricardo Baitelo:

Além do enorme potencial em terra, já se fala na perspectiva de explorar a energia eólica offshore ou no mar. O potencial realizável ainda vem sendo estimado, mas o valor aproveitável é atualmente calculado em $340 \mathrm{GW}$ (Proventos, 2012). Os parques eólicos no mar apresentam vantagens socioambientais, por não ocupar regiões habitadas e não implicar no deslocamento populacional. Tecnicamente, a constância e a velocidade dos ventos do mar 
favoreceriam a geração de energia; e a baixa distância desses parques eólicos em relação à costa (em comparação às atuais grandes obras energéticas do país) também favoreceria a distribuição de energia. Porém, os fatores limitadores à exploração desse potencial são os custos ainda elevados, maiores dificuldades de manutenção e principalmente, o grande potencial remanescente de eólicas em terra que possui implementação menos complexa. (BAITELO, 2012).

Logo verificamos que existe terreno para o aumento exponencial na energia eólica, devendo ser aproveitado, visto que o Brasil possui uma fonte de riqueza renovável subutilizada atualmente devido ao seu potencial. A energia eólica gera menos impactos ambientais e sociais, devendo o Estado brasileiro investir cada vez mais nessa forma de energia (BAITELO, 2012). O maior benefício da energia eólica é a baixa geração de gases de efeito estufa, sendo uma energia verdadeiramente renovável, diferentemente das hidrelétricas que obtiveram esse "selo" de forma falaciosa. A baixa emissão de gases por energia eólica é aludida por Baitelo:

Dentre os principais benefícios ambientais da geração eólica, está a baixa emissão de gases de efeito estufa atrelada à cadeia energética do setor. A operação dos parques não apresenta emissão de gases e a produção e transporte de pás e torres implica em emissões de apenas 9 $\mathrm{g}$ de $\mathrm{CO} 2$-equivalente para cada $\mathrm{kWh}$ gerado, ou cerca de 100 vezes menos do que as emissões médias de uma térmica a carvão. (BAITELO, 2012)

Além de reduzir emissões aéreas de usinas termelétricas, vale ressaltar que a baixa emissão de gases de efeito estufa está entre os principais benefícios ambientais da geração eólica. A operação dos parques não apresenta emissão de gases e a produção e transporte de pás e torres implica em emissões de apenas $9 \mathrm{~g}$ de $\mathrm{CO} 2$ equivalente para cada $\mathrm{kWh}$ gerado, ou cerca de $1 \%$ das emissões médias de uma térmica a carvão (BAITELO, 2012)

Além da baixa emissão de gases naturais do efeito estufa, a obra não causa a metilização do solo, contaminando as populações em volta dos parques eólicos como ocorre nas regiões que recebem as hidrelétricas no Norte do país. Percebemos outra grande vantagem nessa forma de produção de energia que é a possibilidade de se adequar outra forma de exploração econômica no parque, como a agricultura e a criação de gados, os setores produtivos em que o Brasil mais exporta (BAITELO, 2012).

Portanto percebemos que energia eólica é capaz de diminuir os danos ambientais, sendo compatível com o ideal de desenvolvimento sustentável, alcançando as dimensões elencadas por Sachs e Juarez. Sendo capaz de aliar a produção de energia, com outra fonte de 
lucro como a pecuária, um dos negócios mais rentáveis do país, com grandes taxas de importações e com lucros exorbitantes. Nesse sentido já existem exemplos no Brasil bemsucedido de parques eólicos, como por exemplo, o parque de Osório, comprovando que é possível mais investimentos nesse setor.

\subsection{PARQUE EÓLICO DE OSÓRIO}

O parque fica na região sudeste do país e até 2015 era considerado o maior parque eólico da América Latina com capacidade de 150 MG de energia instalada (MME. 2011). Entretanto com a construção do Parque Eólico Geribatu, no município de Santa Vitória do Palmar, no extremo Sul gaúcho, o parque de Osório perdeu o posto de maior parque da América Latina. Percebemos que o Brasil realiza investimentos no setor eólico, mas devido a sua potência e disponibilidade, deveria haver muito mais investimento em uma fonte de energia que é capaz de abastecer a metade da população do Rio Grande Do Sul, aliado com a preservação ambiental conforme consta:

Está subdividido em três parques: Osório, Sangradouro e Índios com capacidade de produzir $150 \mathrm{MW}$ de energia, potência suficiente para abastecer anualmente o consumo residencial de cerca de 650 mil pessoas (50\% da população de Porto Alegre). Fonte inesgotável de energia limpa produzida pelos ventos. O Parque mantém intacta toda a fauna e flora dos campos onde se situa, preservando as atividades produtivas da região. (BRASIL, 2011)

Percebemos o benefício do parque eólico na criação de empregos direitos e principalmente na questão ecológica, visto que o Parque seguiu o artigo 12 do protocolo de Kyoto que versa sobre a necessidade e energia limpa, conforme se observa:

O parque gerou cerca de 500 empregos diretos, além da contribuição para a ecologia através da redução de 148.750 toneladas de gás carbônico. Esta redução ocorre pela substituição de combustíveis fósseis pela geração de energia limpa produzida pelos ventos. O parque segue a Modalidade de Desenvolvimento Limpo prevista pelo artigo 12 do Protocolo de Kyoto. O investimento nos Parques Eólicos de Osório somou até agora R \$ 670 milhões. Os recursos são provenientes de capital inteiramente privado, não especulativo, gerador de infra-estrutura. Partes dos investimentos foram financiados pelo Banco Nacional de Desenvolvimento Social (BNDES) por meio de um consórcio firmado entre os bancos $\mathrm{ABN}$ Amro, Banco do Brasil, Banrisul, BRDE, Caixa RS e Santander. Toda essa estrutura financeira recebeu da Revista Euromoney, o prêmio "Deal of the Year 2005 da América Latina", no segmento de energias renováveis. (NERY, 2006). 
O parque consegue aliar a necessidade e gerar o crescimento energético com a criação de gados e agricultura no terreno e até sendo atração turística na cidade, pois em 2016 a parte de Osório foi aberta para passeios gratuitos para conhecer o funcionamento. Além de ser utilizado como rota turística, antes mesmo da sua criação, já houve benefícios, pois o imposto gerado do Parque eólico foi capaz de pagar o salário dos servidores da prefeitura de Osório no ano de 2006, como se percebe na reportagem do site do governo do Rio Grande Do Sul:

A construção do maior parque eólico da América Latina já traz inúmeros benefícios a Osório, mesmo um ano antes de começar a gerar energia. Além dos 500 empregos criados no município, Osório recebeu R \$ 258 mil de ISSQN (Imposto Sobre Serviços de Qualquer Natureza) em dezembro e fechará janeiro com um valor superior a $\mathrm{R} \$$ 800 mil. A informação foi dada pelo vereador Martin Tressoldi (PP) ao secretário de Energia, Minas e Comunicações, Valdir Andres. Os recursos vindos das empresas prestadoras de serviço ao parque eólico pagam sozinhos a folha de pagamento da prefeitura de Osório, que fica em torno de R 750 mil, destaca Tressoldi. Como eu sempre disse, Osório tirou na loteria ao ganhar a instalação da maior obra em construção no Estado hoje, diz Andres. O parque eólico de Osório, da empresa Ventos do Sul (consórcio entre a espanhola Enerfin, do grupo Elecnor, a gaúcha CIP Brasil e a alemã Wöbben) terá 150 Megawatts (MW) de potência instalada e invesitmento de $\mathrm{R} \$ 670$ milhões, sendo $69 \%$ financiado pelo BNDES. (RIO GRANDE DO SUL, 2017).

Portanto são clarividentes os benefícios que a energia eólica traz a comunidade, sendo uma realidade e não uma expectativa, demonstrando que basta haver maior incentivo do Estado para promover mais parques eólicos pelo país, gerando energia renovável, verdadeiramente limpa diferentemente da falácia de energia renovável através de hidrelétricas que o governo insiste. Logo, para que haja consonância com o preceituado pelo conceito e dimensões do desenvolvimento sustentável, o Brasil deve optar por mais incentivo às energias solares e eólicas e fomentar a pesquisa para novas energias renováveis.

\subsection{ENERGIA SOLAR NO BRASIL}

A energia solar é uma ótima alternativa renovável, sendo muito utilizado mundo a fora e o Brasil possui todos os requisitos essências para a sua exploração. O Brasil é um país com dimensões continentais, existem Estados que possuem grandes temporadas de sol que devem ser exploradas. Percebe-se que há exploração em solo nacional, todavia, todo esse potencial energético ainda se encontra subutilizado, pois a energia solar poderia ser capaz de suprir as necessidades do país como alude Baitelo: 
Dados do atlas Solarimétrico do Brasil (2004) indicam que o país tem uma média anual de radiação no território nacional entre 1.642 e 2.300 $\mathrm{KWh} / \mathrm{m} 2 /$ ano. Se apenas $1 \%$ dessa energia fosse aproveitada, toda a demanda brasileira por eletricidade poderia ser atendida. (BAITELO, 2012).

Durante muito tempo o valor dos equipamentos foi utilizado como entrave para o investimento nas casas pelos particulares e pelo Estado. Entretanto, percebemos que com o passar do tempo, houve uma maior popularização nos preços, superando essa barreira econômica, fazendo com que o mercado de placar solares tenha grande crescimento e com a tendência é de baratear ainda mais os custos como demonstra Baitelo no texto "O setor elétrico brasileiro e a sustentabilidade no século XXI":

O mercado mundial de painéis fotovoltaicos apresentou um crescimento anual entre 30 e $40 \%$ nos últimos cinco anos, com destaque para um crescimento de 67\% em 2011. As células fotovoltaicas têm registrado considerável queda de preço de cerca de $10 \%$ ao ano. Na Europa, o custo de geração solar deve equiparar-se ao da geração por gás natural até 2015. No Brasil, o custo de geração solar fotovoltaica e as tarifas residenciais praticadas pelas concessionárias já se equiparam na maior parte dos estados brasileiros, por conta de fatores como os altos indices de radiação solar em boa parte do país e dos altos custos de eletricidade praticados por algumas distribuidoras (BAITELO, 2012).

Com a evolução tecnológica e a constante preocupação dos cientistas no progresso das energias renováveis, além dos parques solares, existe a possibilidade de explorar a energia solar através de usinas heliotérmicas. Sobre essa usina, Baitelo explica que:

Outro tipo de geração solar é o das usinas heliotérmicas, ou sistemas de energia solar concentrada (CSP). A produção de eletricidade é similar às termelétricas, com a diferença que a energia é obtida pela concentração de radiação solar e convertida em vapor ou gás de alta temperatura. Grandes espelhos concentram a luz em uma única linha ou ponto; o calor produzido é utilizado para gerar vapor quente e de alta pressão, movimentando turbinas que geram eletricidade. Os principais projetos estão localizados atualmente na Espanha e nos Estados Unidos, mas esses sistemas são apropriados para regiões com altos índices de radiação solar direta, como o nordeste brasileiro. (BAITELO, 2012).

O maior benefício ambiental que percebemos é a baixa emissão de gases do efeito estufa, bem como os poucos impactos sociais com a construção do parque solar. Sobre a pouca emissão de gases, Baitelo referência nacional no assunto afirma que:

Em termos ambientais, a geração solar se destaca pela baixa emissão de gases de efeito estufa em sua cadeia energética - inferior a $30 \mathrm{~g}$ de $\mathrm{CO} 2$ eq/ kWh produzido - e na possibilidade de minimização dessas emissões 
no caso de uma produção nacional baseada em insumos energéticos renováveis. (BAITELO, 2012).

Outro benefício importante com o Estado investindo mais no setor solar é a produção de empregos que pode acontecer. Percebemos que o Brasil deve aproveitar o silício para a fabricação de placas fotovoltaicas, gerando centenas de postos de trabalho como alude Baitelo:

O incentivo ao emprego de paineis solares deve vir acompanhado de um plano para a consolidação de um parque produtivo nacional, aproveitando o enorme potencial de silício e a possibilidade de produção de silício em grau fotovoltaico para os paineis. No caso do estabelecimento de fábricas de montagem de paineis importados no país, haveria um ganho substancial de empregos nas áreas de instalação, manutenção (ou três quartos dos empregos totais), mas perderia-se a possibilidade de gerar empregos na fabricação desses paineis, favorecendo a mão de obra de países de origem, notadamente a China. Desta maneira, são evidentes as vantagens no investimento em tecnologia nacional para o desenvolvimento dos painéis solares no Brasil. (BAITELO, 2012).

Percebemos que existem parques solares bem-sucedidos em solo nacional, mas a quantidade é ínfima perto do potencial que o país possui, devendo haver o investimento por parte do governo. Utilizaremos como exemplo bem-sucedido em solo nacional o Parque Solar Lapa, localizado na cidade de Bom Jesus no Estado da Bahia, o maior parque solar do país que possui a capacidade total de $158 \mathrm{MW}$ atendendo ao consumo de 166 mil famílias, conforme consta na reportagem da gazeta do povo:

O início do funcionamento das estruturas está previsto para o segundo semestre de 2017. Juntas, elas serão capazes de atender a necessidade de consumo energético de 336 mil residências brasileiras, evitando a emissão anual de 316 toneladas de dióxido de carbono (CO2) à atmosfera, detalha a empresa. O novo parque solar terá capacidade de 158 megawatts de geração energética, sendo capaz de produzir, por ano, em torno de 340 gigawatts. A porção é suficiente para atender a necessidade de consumo energético anual de, pelo menos, 166 mil domicílios brasileiros. Na construção, a Enel deve investir US\$ 175 milhões. (GUADAGNIN, 2016).

Portanto verificamos total possibilidade do Estado brasileiro promover o desenvolvimento sustentável em sua forma mais completa, respeitando as dimensões defendidas por Sachs (1993) e Juárez (20011) que são econômicas, ecológicas, sociais, culturais, éticas, espacial, psicológica e ética-política desde que modificando a sua política nacional de investimentos energéticos, fomentando a construção de parques eólicos e solares que serão capazes de aliar o crescimento energético e econômico. 


\section{CONSIDERAÇÕES FINAIS}

Este artigo se propôs demonstrar a transição do conceito de desenvolvimento que sempre teve relação direta com o ideal de crescimento econômico, para desenvolvimento sustentável, um princípio constitucional extremamente importante para a concepção de Estado de Direito Ambiental em que o Brasil se encontra. Para além do conceito geral de desenvolvimento sustentável, autores como Sachs (1993) e Juarez de Freitas (2011) defendem que o conceito possui dimensões que são ecológicas, social, econômica, espacial, psicológica, ética, cultural e jurídico-política.

Observamos que o desenvolvimento sustentável para os autores só acontecerá com a satisfação de todas as dimensões e a partir desse entendimento concluímos que o Estado brasileiro deve investir em energias renováveis como solar, eólica e as novas que surgirem. Essa necessidade de investimento nesses setores ocorre devido à política de maiores investimentos em hidrelétricas, pois essas representam mais de $60 \%$ da matriz energética nacional, sendo necessário promover uma segurança energética, ou seja, ter outros meios capazes de satisfazer a necessidade de energia da população se ocorrer algum problema com a principal fonte de energia e principalmente pelos danos causados pela principal fonte de geração energética do país, visto que os grandes projetos como as hidrelétricas causam grandes danos socioambientais e tais danos são totalmente incompatíveis com o conceito e dimensões do desenvolvimento sustentável.

A conclusão dessa pesquisa nos deixa claro que é extremamente necessário à reflexão sobre o princípio do desenvolvimento sustentável visto a sua importância para o meio ambiente, bem como é perceptível que o princípio do desenvolvimento sustentável pode ser alcançado em solo nacional com o potencial solar e eólico do país. Inclusive já havendo exemplos bem-sucedidos em solo nacional como foi demonstrado no trabalho. Sendo assim o desenvolvimento sustentável deve ser fomentado pelas instituições democráticas do país, principalmente pelo Estado através de políticas públicas, parcerias pública- privado para incentivar o investimento em mais parques eólicos e solares, assim como promover a criação de novas energias renováveis que no futuro possam ser mais benéficas para a sociedade, gerando menos poluição ao meio ambiente e um real desenvolvimento sustentável. 


\section{REFERÊNCIAS BIBLIOGRÁFICAS}

AS DIMENSÕES do desenvolvimento sustentável. Disponível em: http://www.publicadireito.com.br/artig os/?cod=8b9b3436fc4466e 9 .

[ca 2015]. Acesso: 10 Abr 2019.

AQUINO, R. O maior projeto de produção de energia está no Brasil. Disponível em:http://gestaoverdeunifor.blogspot.c om/2011/09/o-maior-projeto-deproducao-de-energia.html. Acesso: 26 abril 2019.

BERMANN, C. O setor elétrico brasileiro no século 21: cenário atual e desafios. In: MOREIRA, P. F. et al. O setor elétrico Brasileiro e a sustentabilidade no século 21: Oportunidades e desafios. Brasília: Rios Internacionais, 2012.

BAITELO, R. Fontes alternativas de geração de energia. In: MOREIRA, $\mathrm{P}$. F. et al. O setor elétrico Brasileiro e a sustentabilidade no século 21: Oportunidades e desafios. Brasília: Rios Internacionais, 2012.

BRASIL. Constituição da República Federativa do Brasil. Promulgada em 05 de outubro de 1988. In: Vade Mecum. 19a ed. São Paulo: Saraiva, 2015. Energética e Elétrica. Disponível em: https://www.epe.gov.br. Acesso: 20 mar 2019.

BRASIL. Parque eólico de Osório (RS) é o maior da América Latina. Disponível em: http://www.brasil.gov.br/noticias/infrae strutura/2011/12/parque-eolico-deosorio-rs-e-o-maior-da-america-latina. Acesso em: 02/05/2019.

CANOTILHO, J. J. G. Direito constitucional e Teoria da Constituição. 2003. p. 468-469.
CORREA, R. A Dimensão Econômica E O Desenvolvimento Sustentável Sob A Ótica De Juarez Freitas. Revista Direito à Sustentabilidade. v. 1, n. 2, 2015. Disponível em: http://erevista.unioeste.br/index.php/dir eitoasustentabilidade/article/view/1235 4. Acesso: 30 mar 2019.

CORSI, F.L. Notas sobre desenvolvimento e ecologia. In: SIMONETTI, M. C. L. A (In) sustentabilidade do desenvolvimento: meio ambiente, agronegócio e movimentos sociais. Marília: Oficina Universitária, 2011.

CONAMA. O futuro Que

Queremos, de 22 de junho de 2012. Disponível em: http://www.mma.gov.br/port/conama/p rocessos/61AA3835/O-Futuro-quequeremos1.pdf. Acesso: 15 mar 2019.

FREITAS, J. Sustentabilidade: direito ao futuro. Belo Horizonte: Fórum, 2011. 340 páginas, p. 147.

FREITAS, $\mathrm{J}$.

Sustentabilidade: direito ao futuro. 3 ed. Belo Horizonte: Fórum, 2016.

GUADAGNIN, C. Italiana Enel investe $R \$ 1,3$ bilhão em dois projetos de solar e eólica na Bahia. Gazeta do Povo. 25 abr 2016. Disponível em: https://www.gazetadopovo.com.br/eco nomia/energia-e-

sustentabilidade/italiana-enel-investe-r13-bilhao-em-dois-projetos-de-solar-eeolica-na-bahia-dhqsqy05zo1wb0 8uwo8fa2h3r. Acesso: 01 dez 2018.

Imposto gerado por parque eólico paga folha de prefeitura de Osório. Disponível em: https://estado.rs.gov.br/impostogerado-por-parque-eolico-paga-folhada-prefeitura-de-osorio. Acesso: 30 out 2018.

JACOBI, Pedro. Educação ambiental, 
cidadania e sustentabilidade. Cadernos de Pesquisa, n. 118, mar. 2003. p. 189205.

MOREIRA, P. F. et al. O setor elétrico Brasileiro e a sustentabilidade no século 21: Oportunidades e desafios. Brasília: Rios Internacionais, 2012.

\begin{tabular}{l}
. Ministério de Minas e \\
\hline Energia. Empresa de Pesquisa \\
Energética. Matriz Energética e \\
Elétrica. $\quad$ Disponível em:
\end{tabular}
https://www.epe.gov.br. Acesso: 20 mar 2019.

Ministério de Minas e

Energia. Renováveis devem manter participação de $43 \%$ na matriz energética em 2017. 30 mar 2017. Disponível em: < http://www.mme.gov.br/web/guest/pag ina-inicial/outras-noticas/-

/asset_publisher/

32hLrOzMKwWb/content/renovaveisdevemmanter-participacao-de-43-namatriz-energetica-em-2017> Acesso: 12 mar 2019.

NERY, G. L. Protocolo de Kyoto. 2006. Disponível em: <https://www.egov.ufsc.br/portal/sites/ default/files/anexos/26745-26756-1-

PB.PDF> Acesso: 1 nov 2018.

PARANÁ. Prefeitura do Paraná. Meio ambiente. Disponível em: <http://www.meioambiente.pr.gov.br/ modules/conteudo/conteudo.php?conte $\mathrm{udo}=26>$ Acesso em 15 mar 2019.
PASSOS, P. N. C. A conferência de Estolcomo como pomnto de partida para a proteção internacional do meio ambiente. Revista Direitos Fundamentais \& Democracia. Unibrasil. v. 6. 2009

RIO GRANDE DO SUL. Município de Osório. Parque Eólico. Disponível em: http://www.osorio.rs.gov.br/site/turism o/visualizar/id/22/?Parque-Eolico.html. Acesso: 30 out 2018.

SACHS, I. Estratégias de transição para o século XXI. In: BURSZTYN, M. Para Pensar o Desenvolvimento Sustentável. São Paulo: Brasiliense, 1993. p. 29-56.

Desenvolvimento:

includente, sustentável, sustentado. Rio de Janeiro: Garamond, 2004.

Prefácio. In: VEIGA, J. E. Desenvolvimento sustentável: o desafio do século XXI. Rio de Janeiro: Garamond, 2008.

SOLARVOLT. Usinas solares: conheças as 7 maiores do mundo. Disponível em:< https://www.solarvoltenergia.com.br/bl og/maiores-usinas-solares-do-mundo/> . Acesso: 02 maio 2019.

HUNT. E K. História do pensamento econômico: uma perspectiva crítica. $2^{\mathrm{a}}$ ed. Rio de Janeiro: Elsevier, 2005.

NETO, J. M. C. A. Energia Eólica e Solar: Fontes Alternativas de Geração ou Indispensáveis ao Desenvolvimento Sustentável?. Complexitas - Rev. Fil. Tem. Belém, v. 4, n. 2, p. 48-68, jul./dec. 2019. Disponível em: http://www.periodicos.ufpa.br/index.php/complexitas/article/view/7787>. Acesso em: 30 de janeiro de 2020. 